\title{
Research on the Impact of Online Courses on Students' Learning Efficiency Under the Background of the Epidemic
}

\author{
Shuyu Lin*
}

\author{
Fujian Normal University, Fuzhou, 350007, China \\ *Corresponding author.Email: susielin825@gmail.com
}

\begin{abstract}
The outbreak of the new crown pneumonia has caused the people across the country to suspend work for a long time, and students' studies and school start times have been affected to varying degrees. In order to ensure that while fighting pneumonia, it does not affect the quality of education and classroom efficiency to the greatest extent, online teaching has entered the eyes of students to better guarantee classroom teaching during the epidemic. Nowadays, with the advent of the era of big data, informatization is becoming more and more important in daily life, and online teaching is still the direction of future development, occupying a certain important position in the history of education. How to ensure students' learning enthusiasm and teaching quality through online teaching, and to improve students' learning efficiency, is the most important problem in current online teaching and the most worthy of solution.
\end{abstract}

Keywords: epidemic, online class, efficiency

\section{INTRODUCTION}

During the prevention and control of the new crown pneumonia epidemic, in order to avoid cross-infection caused by the movement of personnel and ensure the safety of teachers and students, universities and colleges and universities in accordance with the requirements of the Central Leading Group for Response to the New Coronary Epidemic "Guiding Opinions on Doing a Good Job in the Organization and Management of Online Teaching in Ordinary Colleges and Universities during the Period of Epidemic Prevention and Control", implemented the policy of "stopping classes without stopping teaching, and without stopping school", and adopted active countermeasures to organize a large-scale and extensive organization in history, Online teaching that takes a long time, has a large number of classes, and covers various subjects and professional courses [1]. Online teaching is the main teaching method adopted by school education in the prevention and control of the new crown pneumonia epidemic. It is an important measure for relevant departments and schools to change the traditional teaching mode in order to adapt to the changes in the environment in special periods to ensure the normal development of teaching. The adaptation of the educational ecosystem to the environment is to a large extent not through changing the environment, but through its own changes [2]. This article mainly conducts an in-depth analysis of the new problems faced by online classrooms and the factors affecting student learning efficiency during the epidemic period, and proposes recommendations to provide references and references for promoting the normalization of online teaching and improving the level of teaching governance.

\section{NEW PROBLEMS FACED BY ONLINE CLASSROOMS}

Online teaching is relatively convenient and fast for teachers and students in isolation at home. Through online teaching practice, it is proved that online teaching is successful and effective, and it has handled the relationship between home isolation and normal teaching in epidemic prevention and control. Various colleges and universities actively use online teaching, which significantly reduces the impact of the epidemic on the teaching progress and avoids the risk of epidemics caused by on-site teaching, which has been widely praised by teachers and students [3]. However, in the process of online teaching practice, due to the relatively backward network foundation in some areas and the relatively weak online teaching resources of some schools, online teaching is facing a series of new situations and new 
problems, which urgently arouse the attention of relevant departments and solve them properly [4].

\subsection{Network hardware cannot meet existing needs}

\subsubsection{The student's network problem}

Due to the winter vacation, most of the students returned to their hometowns, and some students' hometowns are located in remote areas and living conditions are relatively difficult [5]. The network environment of different regions and even different counties and cities in the same province is quite different. Some teachers and students living in rural, mountainous and remote or border areas are greatly affected by network conditions and network teaching equipment. During the investigation, students from remote areas from their hometown reported that the internet is not good. According to the survey, most students use mobile phones to go online, and the network and traffic are switched to classes at any time. Some students can only use mobile phone data to surf the Internet because there is no internet at home. According to students in Luolong County, Qamdo, Tibet, they have to go to relatives to take online classes without $\mathrm{Wi} \mathrm{Fi}$ at home. Some students in Qinghai reported that they need to go to the neighbor's home to rub the Internet in class. Although some students can use the mobile phone data, they can only find the signal and surf the Internet outdoors because of the poor signal in their hometown [6]. Internet hotspots such as Tibetan students searching for mobile phone networks in snowy areas and taking online classes on snow-capped mountains at an altitude of 4580 meters exist in many ethnic regions. For example, there is a herdsman in Hulunbuir, Inner Mongolia, who has 9800 acres of grassland. He moved his family for online lessons for children; in the remote mountainous areas of Changyang and Wufeng Tujia Autonomous County, Hubei, students need to build sheds on the mountains to build "cloud classrooms" for online lessons. A student reported that "to sum up the difficulties of online classes in eight words: difficult for teachers, difficult for classmates. Not all students have the conditions to have unimpeded access to the Internet. The rural students in Wufeng County, Yichang, where I am, have to wake up early in the morning to find places with good signals. In order to have classes, my grandfather set up a shed on the mountain [7]. It's sad to see it. " Even in some rural areas, there will be frequent power outages during the day, resulting in wifi interruption. In addition, mobile phone traffic is limited, so it often happens that classes cannot be attended in time during the day.

\subsubsection{The network problem of the instructor}

Due to the winter vacation, some teachers returned to the country. The network signal in the countryside is not as good as in the cities. The outbreak of the new crown epidemic and the isolation of the "city closure" are emergencies. Some teachers did not bring their computers home with them. Mobile Internet access has limitations in software selection and platform resource sharing, affecting the quality and effectiveness of online courses. The network of the teacher's equipment and the network of the selected software platform are a key factor in the success of online courses. For example, the fluency of the network speed platform, the stability of the teaching platform, the clarity of the screen and audio, the timeliness of teacher-student interaction, and the smoothness of file transmission affect the quality of online teaching.

\subsubsection{Software platform network problem}

The network teaching platform is affected by server quality, equipment system, network settings and other aspects. The network signal is unstable or cannot enter the platform from time to time. It is understood that the online teaching platforms selected by teachers mainly include a series of learning software platforms such as QQ group, WeChat group, Tencent conference, Tencent classroom, Xuetong, Dingding, and enterprise WeChat. Due to the influence of the network and functions of these software and platforms, there are some problems in the use of online teaching. For example, the learning pass platform is easy to get stuck and crash, QQ group live broadcast and sharing screens get stuck, and the splash screen is serious. The traces are more troublesome, "Ding Ding" is cumbersome and as a designated platform for digital campus home-school communication, parents entering the classroom will affect the teacher's recording of students' check-in status, etc.

\subsubsection{The issue of saturation of Internet usage}

During the prevention and control of the new crown epidemic, teachers and students from all over the country increased their use of the Internet through online teaching and online learning through online education platforms.

\subsection{The overuse of the Internet has three effects}

First, the overloaded network operation status causes the network to freeze, get stuck, the network speed is slow, the information is delayed, or the screen is not reflected. In an environment where the network is extremely unstable and during peak periods, there will also be teacher cards and student cards, which cannot enter the live broadcast room, the class page cannot be loaded, the homework cannot be uploaded, the homework data is lost, the learning software is crowded, and the platform crashes Wait for a series of questions [8]. 
Second, the increase in network usage has led to an increase in user mobile phone data traffic, overpayment of mobile phone bills, and an increase in network broadband charges. It has been reported that a student incurs as much as 700 yuan in phone bills for online classes a month. According to a sample survey, about $46 \%$ of students report that their home is in ethnic regions or rural areas and the internet is not good. About $2 \%$ of students were unable to access the platform or were disconnected during class, sometimes as high as $8 \% .68 \%$ of the students said that they mainly use traffic and hotspots to attend classes, and their phone bills are higher than usual.

Third, due to the influence of the Internet, some students cannot study online on time, which affects the learning effect, and also feels annoyed because they cannot keep up with the pace of the classroom. A few students contacted the teacher to make up the lesson after class, which also increased the teacher's workload.

\section{SUBJECTIVE FACTORS THAT AFFECT STUDENTS' LEARNING EFFICIENCY IN ONLINE CLASSES}

\subsection{Some students are not familiar with webcasting}

The results show that the proportion of people who are very familiar and very unfamiliar is relatively small, and the proportion of people who are a little familiar and unfamiliar is the same; most students $(59.46 \%)$ have more than two video software installed on their mobile phones; $77 \%$ of students have watched the live broadcast; The largest proportion of watching live content is entertainment, followed by games and learning [9]. Cross-analysis shows that the proportion of students who have watched the live broadcast is increasingly familiar with the live broadcast.

\subsection{Long-term online teaching reduces students' attention}

According to the survey, some high school students, online classroom teaching maintains the same rhythm as the usual offline teaching mode, starting at 6 in the morning and ending at 10 in the evening. The highintensity online course teaching makes students lose interest in this and cause attention, reduce the efficiency of learning.

\subsection{No teacher face-to-face surveillance}

Online classroom teaching makes some students think that there is no learning atmosphere and they can't learn. In online classroom teaching, students and teachers cannot have direct face-to-face contact. Therefore, teachers do not know whether students are listening carefully. It is precisely because of this situation that students think that the teacher cannot see themselves and will not study seriously, which greatly reduces the learning efficiency, even after a lesson, they do not learn anything at all.

\section{SUGGESTIONS ON IMPROVING ETHNIC ONLINE TEACHING}

Although the new crown pneumonia epidemic is sudden, and schools have no time to prepare for the recording and broadcasting of online courses during the winter vacation, it also exposes some shortcomings in the field of online teaching. National colleges and universities, as colleges and universities, not only have the common problems of online teaching in colleges and universities, but also have the heterogeneity problems that are different from other colleges and universities because the source of students is mainly from ethnic regions or ethnic minorities. Online teaching or online and offline hybrid education will be the future development trend [10]. It is recommended that relevant departments take the epidemic as an opportunity to start with the following aspects to promote the continuous development and improvement of online teaching in ethnic colleges.

\subsection{Increase network infrastructure construction in ethnic areas, especially remote farming and pastoral areas}

First, it is recommended to increase the popularity of the network in ethnic areas and rural areas. The state needs to improve the network infrastructure construction in remote areas of ethnic minorities, remote mountainous areas, and remote towns and towns, expand the application and use of $4 \mathrm{G}$ and $5 \mathrm{G}$ in remote areas of ethnic minorities, and strengthen network coverage. In particular, targeted poverty alleviation needs to increase the construction tasks of telecommunications, mobile, China Unicom, radio and television pilot projects, and open the last mile of the network for children in ethnic areas, remote mountainous areas and rural areas to solve the problem of communication network demand.

Secondly, it is recommended to increase the intensity of preferential tariff policies. During the prevention and control of the new crown epidemic, network operators such as China Telecom, China Mobile, China Unicom, Radio and Television, etc. should provide preferential tariff policies, especially for ethnic minority areas and remote mountainous areas, and provide special subsidies such as data packets to students from poor families.

Third, it is recommended to implement a subsidy policy for network expenses for school teachers and students. On the one hand, the school grants subsidies to teachers and students for mobile phone calls and Internet access fees based on actual conditions. At present, some schools pay 30 yuan to students and some 100 yuan. 
There is a big gap between the cost of students' actual Internet demand. It is recommended to increase subsidies and increase subsidies for teachers' online fees. On the other hand, it is recommended that, under the impetus of the government, Internet providers such as China Mobile, China Telecom, China Unicom, and Radio and Television provide corresponding free data packages or free upgrades.

Finally, in ethnic areas, we must strengthen the construction of community public service facilities. For example, the community is equipped with public library and reading room, equipped with desktop computers or computer rooms, which can be used by community residents to study at ordinary times, and provide convenient conditions for online lessons for students or residents who do not have computers at home during extraordinary times. In short, when a policy is finally successfully realized, in addition to the three important influencing factors of the content of the policy, the quality of the executor, and the means of implementation, there is also a very critical element-the conditions for policy implementation. Similarly, the implementation of online teaching work also needs to consider the implementation conditions of educators, that is, the execution environment and execution resources. Therefore, relevant departments should increase infrastructure construction in ethnic areas, remote mountainous areas, and villages, increase network service projects, improve teaching environment implementation conditions, increase support for tariff policies, and improve the coverage and popularization of the network security system in all rural areas across the country.

\subsection{Train teachers}

The epidemic has forced offline teaching to be converted to online. This article believes that online teaching is not a stopgap measure. After the epidemic, online teaching will become a mode of talent training, or at least a supplementary form of offline teaching. In other words, the combination of online and offline hybrid teaching and hybrid training model will become the new normal of talent training in the future, especially for teacher training and training, the online model has great advantages.

\section{CONCLUSION}

All in all, during the epidemic, the online teaching of "no class suspension" can better ensure that students' studies will not be abandoned during the epidemic. This benefited from the development of my country's economy and data informatization, as well as a bold innovation and effective attempt to reform the education field. It can build a better communication bridge between parents and students, allowing students to better develop their own studies and access more knowledge. Of course, for online teaching to achieve good results, it requires the joint efforts of teachers, students and parents, as well as continuous exploration and innovation and accumulation of experience.

\section{REFERENCES}

[1] G. Liu. Exploration of countermeasures for counselors to carry out mental health education under the influence of the new crown pneumonia epidemic[J].Industry and Technology Forum, 2020, vol.19, pp.169-170.

[2] J. G. Zhang, C. C. Xia, T. N. Song. et al. The application and practice of distance network classroom in imaging technology professional probation teaching. China Medical Equipment, 2020, vol.35, pp.42- 45.

[3] A. H. Li, J. Deng. Online teaching research in ethnic colleges and universities in the prevention and control of new crown pneumonia epidemic. Higher Education Research for Ethnic Minorities, 2020, vol.8, pp.70-76.

[4] J. Q. Zhou. Problems and countermeasures of online classroom teaching in primary and middle schools under the new crown pneumonia epidemic: Taking Beijing $x \times$ School as an example. Educational Exploration, 2020, vol.4, pp.14-17.

[5] Y. Wang, G. Y. Zhao, T. Zhao. Study on improving the efficiency of home self-learning of college students in special times. Education Teaching Forum, 2020, vol.44, pp.316-317.

[6] W. Zhao, F. Y. Liu. The problems and countermeasures of students' online independent learning. Hebei Education (Comprehensive Edition), 2020, vol.58(Z1), pp.74-75.

[7] X. L. Zhang, Y. Zhang. Research on the teaching reform of "semi-network classroom" in the "digital electronic technology" of independent colleges and universities. Journal of Science Education (Middle Period), 2017, vol.10, pp.81-82.

[8] Y. Q. Liu, L. J. Zhou, H. Y. Wei, et al. Analysis of the Status Quo and Satisfaction of College Students' Online Classroom Use. University Education, 2020, vol.1, pp.192-194.

[9] J. W. Guo. Discussion on the Application of Internet Classroom in Internet Teaching. Tian Tian Ai Science (Frontier Education), 2020, vol.11, pp.175.

[10] Y. F. Liang. The teaching path of webcast under the background of "stopping classes without stopping school"__ Taking the course of "Advanced Mathematics" as an example. Hebei Vocational Education, 2020, vol.4, pp.61-64+68. 